\title{
Semanario Pintoresco Español (1836-1857): noticias sobre cultura gallega en la prensa romántica centropeninsular
}

\author{
Semanario Pintoresco Español (1836-1857): News about Galician \\ Culture on the Romantic Press in the Centre of the Peninsula
}

\author{
María Victoria NAVAS SÁNCHEZ-ÉLEZ \\ Juan Miguel Ribera Llopis \\ Universidad Complutense de Madrid \\ Departamento de Filología Románica, Filología Eslava y Lingüística General \\ mvnavas@filol.ucm.es|jumriber@filol.ucm.es \\ [recibido 24/10/2014, aceptado 26/01/2015]
}

\section{RESUMEN}

Vaciado del Semanario Pintoresco Español (1836-1857), publicación periódica de naturaleza miscelánea, impresa desde el centro español y peninsular, para confirmar la atención que la citada revista castellana muestra, en una dinámica ochocentista e iberista, hacia el referente cultural gallego.

PALABRAS CLAVE: Relaciones culturales castellano-gallegas, protoiberismo, Semanario Pintoresco Español.

\section{RESUMO}

Baleirado do Semanario Pintoresco Español (1836-1857), publicación periódica de natureza miscelánea, impresa desde o centro español e peninsular, para confirmar a atención que a devandita revista castelá mostra, nunha dinámica oitocentista e iberista, cara ao referente cultural galego.

PALABRas CHAVE: Relacións culturais galego-castelás, protoiberismo, Semanario Pintoresco Español.

\begin{abstract}
An analysis of the Semanario Pintoresco Español (1836-1857), a periodical and miscellaneous Castilian publication, which will reveal its numerous references to Galician culture presented from its Iberian 19th century viewpoint.
\end{abstract}

KEY WORDS: Cultural relationships between Castile and Galicia, protoiberisme, Semanario Pintoresco Español.

Navas Sánchez-Élez, Ma V. y Ribera Llopis, J. M. (2015): “Semanario Pintoresco Español (1836-1857): Noticias sobre cultura gallega en la prensa romántica centropeninsular”, Madrygal (Madr.), 18, Núm. Especial: 481-493. 
1. Esta colaboración acerca del noticiero sobre cultura gallega en el Semanario Pintoresco Español (1836-1857), exponente destacado de la prensa romántica española, forma parte de un conjunto de aportaciones mediante las que ordenamos los contenidos peninsulares no castellanos de dicha publicación, es decir, de las otras culturas del ámbito ibérico, la portuguesa, la catalana, la gallega y la vasca. En este sentido y para encuadrar estas líneas, remitimos a una primera entrega sobre las noticias referidas a la cultura portuguesa en esas mismas páginas (Navas Sánchez-Élez y Ribera Llopis 2014). Allí y sin ánimo de redundar ahora en los mismos datos generales, mencionamos la convocatoria ${ }^{1}$ que nos animó a llevar a cabo el vaciado de la citada revista para aproximarnos a su perfil pan-peninsular; así como al espectro intelectual y político que propició el crecimiento del discurso regionalista e iberista en el conjunto del cual el Semanario Pintoresco Español nos ofrece hoy una relectura que permite considerarlo como un hito protoiberista. Todo ello, dentro de la evaluación que merece el modelo periodístico del que se partiera así como de su tendencia política de origen y, quizá, de su inesperada derivación ideológica. Reiteramos que, a modo de preámbulo, nos valemos de la presentación redactada en su día.

En todo caso, destacaremos algunas de las cuestiones allí tratadas en el marco de las apreciaciones histórico-periodísticas señaladas por los especialistas: aquellas que van desde la identificación del Semanario Pintoresco Español con las revistas ilustradas de divulgación y entretenimiento, según patrón continental, pasando por la relevancia concedida a los grabados así como al tono entretenido, pero no exento de nivel intelectual, a la hora de presentar sus más variados contenidos, para acabar por contar con destacadas firmas y por pensar en un destinatario medio-burgués, que no eximía de un lector popular merced al precio final (Seoane 1983: 167-170, Sánchez Aranda y Herrera 1992: 130-131, Fuentes y Fernández Sebastián 1998: 65, 66 y 67). Entre estos mismos expertos se valora también cómo la publicación no era ajena a un proyecto de superación económica y moral de alcance estatal, tal vez como eco y herencia de las setecentistas Sociedades de Amigos del País. A propósito de ese perfil, entendemos que todos y cada uno de esos aspectos y criterios del Semanario Pintoresco Español se podían mantener y plasmar a través de materia pluralmente española y peninsular.

Ante la revisión de las entradas que evidencian una creciente toma de conciencia de la polifonía compartida, destacamos cómo la revista supo tomarle el pulso al país y a la península, al tiempo que vehiculaba una red de información entre las comunidades históricas peninsulares, en correspondencia con una sensibilidad que empieza a hacerse evidente a partir de los años cincuenta del ochocientos y merced a nombres de primera línea como Juan Valera. En estas páginas, pues, damos a conocer cómo historia y realidad gallegas pudieron llegar al resto de los destinatarios ibéricos a través del castellano. Y, si para entender la dinámica en que se movió la publicación aún pudiera ser útil recordar cómo se presenta la voz "península" como espacio compartido, y también para estimar cómo se aborda España como un conjunto diferenciado por regiones ${ }^{2}$,

\footnotetext{
${ }^{1}$ II Congreso Internacional 'El Artista'y el 'Semanario Pintoresco Español' en sus aniversarios (Museo Romántico de Madrid, 20-21/10/2011). Véase Arroyo Almaraz (ed.) (2012).

${ }^{2}$ M. E. D. (7-10-1838): "Noticia de las aguas minerales y termales de más nota en el Reino, con expresión de sus principales propiedades", SPE, 132, 727-730; Assas, M. de (13-9-1857): "Nociones fisionómico-históricas de la arquitectura en España. Artículo VII”, SPE, 37, 289-292; Assas, M. de (7-3-1847): "Apuntes para la historia de los trajes en España durante los siglos XII, XIII, XIV, XV y siguientes", $S P E$, 10, 73-74; Anónimo (18-2-1849): “El puente de Ocinos", SPE, 7, 52; El Curioso Parlante (21-3-1852): "Industria de la capital", $S P E, 12,93-95 ;$ Anónimo (19-12-1852): "Siglo XVI", SPE, 51, 407-408; García Escobar, V. (18-12-1853): "La Estrella de Campos”, SPE, 51, 401-403.
} 
aportamos un muestrario de artículos del $\mathrm{Se}$ manario, pasando a centrarnos en esta ocasión en el espacio cultural gallego.

2. Contemplado el Semanario Pintoresco Español mediante un total de noventa y siete entradas, éstas versan tanto sobre historia (2.1.) como sobre tipología, tradiciones y leyendas (2.2.), así como sobre biografías (2.3.) y asuntos de lengua y literatura (2.4.), sin olvidar aspectos relativos a ciudades y parajes, a instituciones y monumentos (2.5.) y, aún, a viajes y viajeros (2.6.). Recordemos, en cualquier caso, que, en ocasiones, el contenido de una misma de aquellas entradas puede derivar hacia más de uno de esos puntos clasificatorios, razón por la cual puede aparecer repetida en la respectiva nota de catalogación que se da al pie de cada uno de los correspondientes grupos que ocupan los apartados siguientes.

2.1. Una colaboración ${ }^{3}$ nos informa del proceso de creación de la "nación céltica de origen", partiendo de la presencia de los testimonios de Estrabón y acerca de sus más antiguos habitantes, pasando por la colonización romana y la visigotización y destacando en sus conclusiones cómo la “(...) región fué dividida de un modo independiente en parte española y portuguesa en el siglo XII", consideración apoyada con datos de orden dinástico, concernientes a la división política entre las coronas castellana y portuguesa.

De contenido histórico más puntual son seis las entradas ${ }^{4}$ de asuntos muy diversos. En primer lugar, con dos colaboraciones en torno al sepulcro del almirante Paio Gómez Chariño en la iglesia de san Francisco en Pontevedra, se documenta la participación gallega en la conquista de Sevilla en el siglo XIII y en la batalla de Pavía. En la tercera se trata y documenta la constitución en 1418 de la Hermandad de Santiago. En la cuarta de aquellas entradas, relato costumbrista, más literario que historiográfico, sobre los contratiempos de los emigrantes que llegan a La Habana y de la oportunidad o no de contar con cartas de recomendación, el protagonista menciona lo siguiente: "Tengo el gusto de presentar à V.S. esta carta de recomendación que me dio en la Coruña Don Rafael Tenreiro y Rivadulla su amigo". La posibilidad de confirmar la historicidad de este personaje resulta tan difícil como las de los otros nombres propios que aparecen en el relato. En todo caso, la mención sirve para aproximarnos a la emigración gallega a Cuba y a la función de los contactos gallegos en La Habana. En la quinta colaboración, al pie de un detallado grabado con dos peregrinos, que portan todos los atributos propios, el artículo, que parte de la etimología latina del término, remite al porqué devocionario de las peregrinaciones, documenta el fenómeno en la Edad Media y sus principales destinos cristianos, añade su vigencia en las tradiciones más dispares, informa socio-culturalmente de las situaciones y las infraestructuras que propició dicho fenómeno y concluye con un párrafo más detallado acerca del destino gallego por excelencia, Santiago, de sus indulgencias, de la pluralidad de orígenes y lenguas de sus visitantes, de los ritos y ceremonias allí desarrollados, de la efeméride del Año Santo y de las gracias obtenidas. Al asunto de esta quinta entrada se

\footnotetext{
${ }^{3}$ Fabre, F. (4-10-1840): “Geografía. Región Galaica”, SPE, 40, 316-318.

${ }^{4}$ Neira de Mosquera, A. (14-8-1853): "Antigüedades de Galicia. Sepulcro del almirante Charino en la Iglesia de san Francisco de Pontevedra", SPE, 33, 261-262; Neira de Mosquera, A. (21-8-1853): "Antigüedades de Galicia. Sepulcro del almirante Charino en la Iglesia de san Francisco de Pontevedra. (Conclusión)", SPE, 34, 270-272; Neira de Mosquera, A. (2-11-1851): "La Hermandad de Santiago. 1418", $S P E$, 44, 346-348; El Fisgón Invisible (19-5-1839): “Costumbres de La Habana. Las Cartas de Recomendación”, $S P E, 20,158-160$; Anónimo (25-7-1841): "Los peregrinos de Santiago", SPE, 30, 233-234; Neira, A. (19-8-1843): "Recuerdos históricos. El Martes de Espíritu Santo de 1697, en Santiago", SPE, 33, 260-263; Neira, A. (27-8-1843): "Recuerdos históricos. El Martes de Espíritu Santo de 1697, en Santiago", $S P E, 35,266-268$; Neira de Mosquera, A. (24-10-1852): "O vota-fumeiro de la catedral de Santiago", SPE, $43,338-340$.
} 
suma la materia tratada en la sexta y última, de acuerdo con la nota a pie de página, y que trata del botafumeiro compostelano. El texto parte de imaginar misterioso, simbólico y solemne el vuelo del incensario para pasar con más precisión a cuestiones de orden etimológico, testimonios, salubridad, descripciones de la sede catedralicia y su botafumeiro, de la ceremonia específica del incensario y del calendario de festividades religiosas en las que se usa.

Las dos colaboraciones previas a esta última, según la nota a pie de página, son la primera parte y continuación de una crónica de una celebración religiosa compostelana, en el marco de la teatralidad barroca; relativa al martes de Espíritu Santo de 1697, dicho festejo se notifica que tuvo lugar en el claustro del Colegio de Fonseca, dando el nombre de su autor, José Ballo de Porras ${ }^{5}$, quien aparece acompañado del portero del citado Colegio, Trasvilla, por único nombre, de "dos continuos del colegio", uno de ellos identificado con un tal Vega, más el "Dr. D. Ignacio Pereira, colegial de Fonseca" y el "licenciado D. Diego Jacinto de Moscoso"7, responsable de una "oración panegírica" al fundador de la institución, el también mencionado D. Alonso de Fonseca. Se informa, asimismo, que el “certamen" lo presidió D. Fabián de Pardiñas ${ }^{8}$. A parte de la noticia de alcance lingüístico y literario, que se recuperará en el apartado correspondiente (2.4.), sobre estos personajes históricos damos cuenta de la información recabada a pie de página. A propósito de estas dos últimas entradas y con alcance histórico, sí cabe destacar la intención conservadora de A. Neira al glosar estas celebraciones tal y como se insiste en el cierre de la colaboración. El escritor se manifiesta a favor de estos actos periclitados y lamenta el espíritu revolucionario que ha impedido su continuidad "(...) en aquellos venturosos tiempos de paz, de religión y de poesía, época dichosa y nacional que han bastardeado las revoluciones y una mano de hierro levantada en el Sena para hacer trizas nuestras lisonjeras esperanzas, y nuestras más santas creencias".

2.2. De tipología gallega, encontramos, por una parte, dos entradas, una anónima y la segunda firmada por José Villa-Amil y Castro 9 . La primera-traducción de una novela francesa que comienza por plantear la correspondencia entre gallegos y auverneses como estereotipos de rústicos-, versa acerca de las peripecias de dos gallegos, ambos mozos de cuerda en Madrid, uno de los cuales, Santiago, ante la decisión de retornar a Galicia elabora una pícara argucia para hacerse con un dinero que no es suyo, mientras que el otro, Pablo, actúa de manera contraria. La segunda entrega, sobre el labrador gallego y de sus labores agrícolas estivales, es un pormenorizado documento que tanto nos explica las tareas ejecutadas como los aperos y otros objetos utilizados durante las mismas, dando cuenta cabal de las voces gallegas que recuperaremos en el apartado correspondiente (2.4.).

Por otra parte, agrupamos tres colaboraciones que responden a la serie "Usos y traj/ges

${ }^{5}$ Autor en castellano, también registrado como José Vallo de Porras, vencedor de las Fiestas Minervales de 1697 (Loa al Espíritu Santo), escritor de Autos sacramentales y paraphrasis de los siete psalmos penitenciales (1702) y patrón de la capilla de Alba de la catedral de Santiago.

${ }^{6}$ Miembro del Colegio de Fonseca, Asistente y Justicia Mayor de la ciudad de Santiago y de su partido, y catedrático de Prima de Leyes de la Universidad Compostelana.

${ }^{7}$ Diego Jacinto Romero de Moscoso y Caamaño (1673-?), cuyo texto se contiene en Oración panegyrica en la festiva solemnidad que annualmente consagran... la ilustre Universidad de Santiago y Colegio principal de Fonseca... a la felice memoria del Excelentissimo Señor D. Alonso de Fonseca Zúñiga y Azebedo..., editado por Antonio Frayz, Santiago, 1697.

${ }^{8}$ Fabián de Pardiñas Villar de Francos, caballero de la Orden de Santiago y deán de la catedral compostelana y participante como poeta en castellano en las Fiestas Minervales.

${ }^{9}$ Anónimo (23-12-1838): "Los dos gallegos. (Traducción de una novelita francesa)", SPE, 142, 819820; Villa-Amil Castro, J. (27-7-1857): "La maya", SPE, 30, 234-235. 
provinciales"10. Las dos primeras van acompañadas de detallados grabados con tipos populares, el primero de los cuales se acompaña de un genérico "Los gallegos", mientras que el segundo alude a los oriundos de Finisterre. La entrada inicial ofrece la curiosidad de que, partiendo de A Coruña, su autor juzga que, incluso en Galicia, se ha operado una nivelación de índole nacional en cuanto a hábitos y modas se refiere. No obstante, la misma firma en su segunda aportación, aprecia diferencias notables entre las comarcas gallegas que, en el caso de la Costa da Morte, le hace buscar símiles de corte romántico germánico, aunque tendrá que reconocer que frente a los rubios teutones aquí se oponen los naturales de "morena tez y serio aspecto, que viven en miserables casucas metidas en un arenal, ó agrupadas á la sombra de un pequeño bosque...".

La tercera de esta serie, a pesar de tener el mismo encabezamiento, se orienta hacia otra materia, la que versa sobre tradiciones y leyendas, y a la que cabe añadir otras tres en$\operatorname{tradas}^{11}$. La última de esa serie y la tercera de las ahora incorporadas, acompañadas ambas de grabados de parajes ourensanos y lucenses, nos acercan a la geografía, a la historia, a las tradiciones y a la arquitectura de sendos santuarios -el de Nuestra Señora de los Remedios en la confluencia de los ríos Barbaña y Miño, y el de los Desamparados en Abades-. Por su parte, el otro texto, calificado como "fenómeno extraordinario", da cuenta por extenso y partiendo del testimonio del cura D. Benito Lareu y Barreiro ${ }^{12}$ del caso de una enferma de "parasismo", Josefa de la Torre, "la enferma de Santa María de Gonzar" (n. 1772/1773$1848)^{13}$, que sobrevive "sin comer ni beber y sin ejercer ninguna de las funciones corporales hace treinta años". El cronista de tal suceso deja abierta la interpretación de dicho fenómeno al perfil religioso o científico de sus lectores. Finalmente y pasados seis años, otro artículo abunda en este mismo hecho, acompañado ahora de una xilografía de la enferma, copia de un original "del artista Cancela, profesor de la escuela de dibujo de la Sociedad Económica de Santiago"14, insistiendo en que se trata de "una pintura verdadera de la situación que tiene invariable desde su último parasismo". De distinta naturaleza es el episodio de la llamada "loca de Roupar", que remite a sucesos verídicos y cronológicamente próximos, a pesar de situarnos ante la espeluznante escena de una enajenada mujer, porque su padre diera muerte a su enamorado, y que se pasea entre escombros del castillo... “(...) pálida y desgreñada que os arrojará piedras diciéndoos con débil voz: huid!, huid! asesinos de Jacobo, huid!!"15.

En alguna ocasión y frente a estos retratos por extenso, se incluyen juicios de valor más concisos y explícitos. Es el caso de escribir que "los gallegos tienen fama de sobrios y de honrados", como leemos en una entrada a propósito de A Coruña, tratada posteriormente

${ }^{10}$ G.L, J. M. (3-11-1839): “Usos y trages [sic] provinciales. Los gallegos”, SPE, 44, 345-347; G. L. (162-1840): "Usos y trajes provinciales. Los gallegos de Finisterre", SPE, 7, 49-52; P.J.G. y C. (13-6-1847); "Usos y trajes provinciales. La fiesta de la virgen de los Remedios en Orense", SPE, 24, 185-188.

${ }^{11}$ Vázquez Varela, V. (22-4-1838): "Fenómeno extraordinario", SPE, 108, 536-538; Neira de Mosquera, A. (20-10-1844): "Sucesos contemporáneos", $S P E, 42,329-330$; Neira de Mosquera, A. (29-7-1851): "Santuario de los Desamparados en Abades", SPE, 26, 203-205.

${ }^{12} \mathrm{~A}$ su escrito se añadió, en 1838, una Breve manifestación de los motivos que impidiendo á Josefa de la Torre comer y beber, hace treinta años vive en continuo ayuno (Coruña: [s.n.], Imprenta de F. Arza), de Vicente Taboada. Esta fecha coincide con la del artículo resumido en SPE, lo que indica la popularidad de este caso.

${ }^{13}$ Además de bibliografía de corte mágico y espiritual sobre este caso, revisado científicamente, veáse Fuentes Barco, García Piñeiro y Angosto Saura (2006).

${ }^{14}$ Juan José Cancela del Río (1803-1886), pintor valorado en especial por sus miniaturas y artista de ideología antiliberal.

${ }^{15}$ Vicetto y Pérez, B. (21-7-1844): “La loca de Roupar”, SPE, 29, 227-228. 
(2.5.); o el de poder leer que "Eso de contentarse con cualquier cosa es muy de gallego, pero уо..."

2.3. En lo que se refiere a material biográfico, el Semanario nos ofrece un perfil del Fr. Benito Feijóo ${ }^{17}$, situándolo en el espectro de una inicial ilustración hispana. No obstante, el anónimo autor que sí informa del origen gallego del personaje -"nació à 8 de octubre de 1676 en Cas de Miro, pequeña aldea de la feligresía S. María de Mélidas en el obispado de Orense"-, no puede todavía destacar la labor que el P. Feijóo tendrá como inicial informador de la cultura y de la lengua gallegas, tal y como le apreciamos hoy. En cambio, otros cuatro perfiles biográficos enfatizan la galleguidad de sus sujetos ${ }^{18}$ : Diego A. Cernadas de Castro, el cura de Fruime -representado con dos xilografías, la segunda en el artículo dedicado al siguiente personaje-, es aquí recuperado no por "coplero" sino por "humanista entendido y un erudito juicioso", confusión que "(...) acontece con frecuencia al tratar de escritores satíricos, sus discursos científicos y sus trabajos literarios sean condenados al olvido, repitiendo, y lo que es peor, adulterando sus versos de circunstancia”, lo cual no le evita al autor del artículo reconocer que en el "fácil y picante versificador" late "la pública vindicta de Galicia", que venía a negar la tópica gallega divulgada en el resto de la Península. Alonso de Fonseca, reconocido entre "los españoles célebres del siglo XVI", no obstante es, asimismo, reubicado en la genealogía eclesiástica de los Gelmírez $\mathrm{y}$ "Como personaje político hace valer en las
Córtes habidas en el Convento de San Francisco de Santiago en 1520 la significación política de su patria". De Juan Francisco de Castro, situado en el esplendor cultural del reinado de Carlos III, se hace hincapié en su educación civil y canónica en la Universidad de Santiago, se le destaca como precursor del estudio del derecho español universitario y como antecedente de otro jurisconsulto gallego, D. José Febrero, y también en que, desde sus cargos eclesiásticos, ayudó a la población gallega más menesterosa y propició la restauración de templos. De Pedro Pardo de Cela, personaje destacado durante el reinado de los Reyes Católicos, se lleva a cabo una revisión histórica que no desatiende la forja del héroe desde una perspectiva nacional gallega.

2.4. La lengua y literatura gallegas aparecen en esta publicación con testimonios galaicoportugueses, reproduciendo una composición de Alfonso X, calificada de "romance" siendo una de las cantigas marianas, -"Esta é como santa María guarecen [sic] en Onna al rey don Ferrando, quando era Mennino, de una gran enfermedade que avia"-; el acta del consistorio de la Hermandad de Santiago de 1416 -traducción iniciada en gallego pero que acaba copiando el original castellano-; y un poema de Macías ${ }^{19}$, que comienza "Cautivo de miña tristura/ ja todos prenden espanto...". Por cierto que el responsable de la segunda colaboración, siglas N.C.C., bajo las cuales se identifica a Nicolás Castor de Caune$\mathrm{do}^{20}$, reproduce el término "portugués" para referirse al idioma en que está escrita dicha

${ }^{16}$ Anónimo (20-3-1852): "Vista de La Coruña", SPE, 13, 97; El Barón de Illescas (24-12-1854): “Congreso doméstico. Sesión del día 24 de diciembre de 1854. A las nueve de la mañana”, SPE, 52, $415-416$.

${ }^{17}$ Anónimo (16-4-1837): "Feyjóo", SPE, 55, 114-115.

${ }^{18}$ Neira de Mosquera, A. (23-2-1851): "D. Diego A. Cernadas de Castro. (El cura de Fruime)", $S P E$, 8, 59-60; Neira de Mosquera, A. (30-3-1851): "Don Alonso III de Fonseca", SPE, 13, 99-100; Neira de Mosquera, A. (27-6-1852): “D. Juan Francisco de Castro", SPE, 26, 201-203; Villaamil y Castro, J. (22-21857): "El Mariscal Pardo de Cela", $S P E$, 8, 61-63.

19 Anónimo (23-9-1849): "Poesías españolas del siglo XIII", SPE, 38, 298-299; Neira de Mosquera, A.(2-11-1851): "La Hermandad de Santiago. 1418", SPE, 44, 346-348; N.C.C. (10-11-1844): "Recuerdos históricos. Los amores de Macías", SPE, 45, 357-358.

${ }^{20}$ Para las siglas por nosotros no identificadas en el momento de la redacción de este trabajo, la consulta de Hernández Sánchez (2012) nos ha ayudado a resolver este caso, dado que el autor se ciñe a los artículos del SPE sobre materia vasca. 
composición, donde cabe entender que lo está en gallego-portugués. También se recogen documentos, frases o léxico en gallego en otras entradas que ubicamos en los apartados complementarios: así, el texto gallego-portugués a propósito de la muerte del mariscal Pardo de Cela (2.3.), donde el castillo de la Frouxeira, posesión y cárcel de dicho personaje, toma la palabra para entonar un planto trovadoresco encabezado con el pie "Ahora chora á casa por seo señor, e se queixa dos criados que lle foran tredores, é diz así..."; y la referencia a léxico rural -"mayo", "mayador", "xestas", "enciño", "abidueira"...-, acompañado en nota a pie de página de la correspondiente explicación, y a oraciones "á as Animiñas, ó á nosa señora dos Remedios" (2.2.) ${ }^{20}$.

Paralelamente, no se evitan consideraciones sobre la propia lengua, calificando el gallego como "dialecto", distinguiéndose en una ocasión dos variantes o "dialectos hijos de un idioma corrupto que nació en medio de la oscuridad de los siglos bárbaros"; a veces y de modo temprano, el cultivo lírico del idioma se menciona mediante las "veinte coplas en gallego", que se incluían en las celebraciones santiaguesas del Martes de Espíritu Santo de 1697 (2.1.), o aquéllas que el cura de Fruime recogía en su faceta, antes referida, de versificador y revindicador de Galicia (2.3.), aunque no se llegan a transcribir ni unas ni otras; o la muestra de oralidad del traductor que ortografía la $<_{0}>$ átona como $<\mathrm{u}>$, por ejemplo, "Estu es muy buenu" o "-Sí, Santiagu, y tumaremus en arriendu una casilla en el caminu real..." (2.2.) $)^{21}$. Resulta propicio informar en este punto de una entrada respecto al donativo bibliográfico del señor Parga y Puga a la biblioteca de la Universidad de Santiago; además de dar la relación de los fondos, destacamos las apreciaciones lingüísticas escritas en torno a la traducción de ciertos significados del español al gallego de acuerdo con un conjunto de "siete mazos de cartas confidenciales" del P. Sarmiento a su hermano, así las voces "arroares" ("ceguera temporal de los atunes"), "carqueixa" ("curas prodigiosas de la carquesia"); también señalamos la valoración que se hace de este tipo de fondos a la hora de "analizar los elementos constitutivos de la nacionalidad literaria", aun pensando en la española, pero animada desde la toma de conciencia del "provincialismo" gallego ${ }^{22}$. No cabe esperar en esta publicación ejemplos de literatura gallega contemporánea, por tanto no sorprende que un anónimo "Soneto. Al Miño" y un "Madrigal. A J..." de Manuel M. Murguía estén en castellano ${ }^{23}$. En cambio y aunque también sea en castellano, pero dada la incidencia que tendrá en la literatura rexurdentista, sí cabe destacar la atención de J. Rúa Figueroa a la figura de Ossián, traduciendo el poema "Carthon" y nombrando en las notas a Macpherson ${ }^{24}$.

\footnotetext{
${ }^{20}$ Villaamil y Castro, J. (22-2-1857): "El Mariscal Pardo de Cela", SPE, 8, 61-63; Villa-Amil Castro, J. (27-7-1857): "La maya", SPE, 30, 234-235.

${ }^{21}$ Neira de Mosquera, A. (12-9-1847): "España pintoresca. El palacio de los Torrechanos vulgo Churruchaos", SPE, 37, 289-291; Figueroa, J. R. (25-5-1851): "Monte Furado", SPE, 21, 461-462; Neira de Mosquera, A.(2-11-1851): "La Hermandad de Santiago. 1418”, SPE, 44, 346-348; Neira de Mosquera, A. (8-5-1853): "Bibliografía. Donativo del Excmo. Sr. Parga y Puga á la biblioteca de la Universidad de Santiago", SPE, 19, 145-150; Fabre, F. (4-10-1840): “Geografía. Región Galaica”, SPE, 40, 316-318; Neira, A. (13-8-1843): "Recuerdos históricos. El Martes de Espíritu Santo de 1697, en Santiago", SPE, 33, 260-263; Neira de Mosquera, A. (23-2-1851): "D. Diego A. Cernadas de Castro. (El cura de Fruime)", $S P E, 8,59-60$; Anónimo (23-12-1838): "Los dos gallegos. (Traducción de una novelita francesa)", SPE, $142,819-820$..

${ }^{22}$ Neira de Mosqueira, A. (8-5-1853): “Bibliografía. Donativo del Excmo. Sr. Parga y Puga á la biblioteca de la Universidad de Santiago", $S P E, 19,145-150$.

${ }^{23}$ Anónimo (25-9-1842): "Soneto. Al Miño", $S P E, 39,312$; Murguía, M. M. (20-4-1856): “Madrigal. A J...", SPE, 16, 128.

${ }^{24}$ Figueroa, J. R. (4-7-1852): “Carthon, poema de Ossian”, SPE, 27, 212-215.
} 
2.5. Aparece en el Semanario Pintoresco Español una descripción geográfica por extenso de la "Región Galaica" 25 , texto que en su contenido geológico, costero, fluvial, mineralógico y botánico está remitiendo al espacio de la Galaecia antigua. Hay que tener esto en cuenta, tanto por los datos con que afianza esas materias como por los que añade de orden histórico antiguo y medieval y también lingüístico. Sobre esta última cuestión (2.4.) y en lo que se refiere a asuntos históricos (2.1.), dichos contenidos quedan reflejados con anterioridad en los apartados correspondientes.

A propósito de parajes en particular y, rescatando tres entradas anteriores acerca de los santuarios de Nuestra Señora de los Remedios (Ourense), de los Desamparados (Lugo) y del valle de Roupar que hemos preferido comentar antes (2.2.) en función de las tradiciones allí conservadas o de un particular caso, contamos con otras diez entregas -ocho de ellas con xilografías paisajísticas (una repetida) y una con la reproducción de una escultura romana hallada en Caldas ${ }^{26}$-. Con contenidos usualmente exhaustivos, destacaremos aquellas consideraciones de cada uno de los lugares donde, a nuestro parecer, se verifican indicios de galleguidad.

Así, a propósito de San Simón y San Antonio (ría de Vigo), donde se insiste en el dato geográfico y geológico, se alude a la antigüedad de sus asentamientos mediante la mención a “(...) los vestigios y ruinas de cimientos que todavía se dejan ver distintamente en una y otra isla", no desestimando asimismo traer a colación la belleza que por su "(...) singular posición (...) es tan maravillosa y encantadora que cuanto se diga de ellas será siempre un reflejo muy pálido". Describiendo la cascada de Toja (Pontevedra) se elogia su naturaleza:

La variedad es la belleza de Galicia, país formado por las mil ramificaciones de las montañas que elevó la mano de Dios para servir de dique al Océano occidental. Sus valles, generalmente de corta estensión, sucédense con asombrosa rapidez ante los ojos del viajero. Ceñidos por la sombría faja de los montes bastan algunos pasos para cambiar el cuadro más triste en la más halagüeña perspectiva, y una colina, una simple roca operan à veces este cambio prodigioso.

Al comentar el Paso del Ulla en san Juan da Cova, el modo de magnificar su hermosura semeja un escenario digno de la literatura de Walter Scott. Más adelante, en la doble versión que se redacta de los desfiladeros de A Coruña, vemos cómo su autor acaba por eliminar un párrafo contenedor de un cierto demérito de las construcciones allí situadas, consideración que en el primer texto achacaría tanto a aquel paraje como a otros conjuntos de ruinas españolas. Al presentar la obra de ingeniería del Monte Furado (Lugo), el escritor lamenta tanto el desconocimiento de Galicia desde el resto de España como la poca estima por parte de sus nativos:

(...) solo le conocen, solo le contemplan y le admiran los que han tenido no sé si la fortuna ò la desdicha de nacer y habitar en ese despreciado rincón de la España occidental, en esa oscura Galicia cubierta para el resto de la Península entre la bruma de sus colinas y la indolencia de sus humildes y descuidados moradores.

Aprovechando que va a detenerse en el puente de Cesures (Pontevedra), el autor relata

\footnotetext{
${ }^{25}$ Fabre, F. (4-10-1840): “Geografía. Región Galaica”, SPE, 40, 316-318.

${ }^{26}$ Taboada y Leal, N. (5-6-1842): "Descripción de las islas de San Simón y San Antonio en la Ría de Vigo", SPE, 23, 181-182; Figueroa, J. R. (15-9-1850): "La cascada del Toja”, SPE, 37, 292-294; Figueroa, J. Rúa (22-9-1850): "Paso del Ulla en San Juan de Cova", SPE, 38, 297-298; Anónimo (13-4-1851): "Desfiladeros de La Coruña”, $S P E, 15,113$; Figueroa, J. R. (25-5-1851): “Monte Furado”, $S P E$, 21, 161-162; Neira de Mosquera, A. (2-5-1852): "El puente Cesures", SPE, 18, 140-142; Neira de Mosquera, A. (1010-1852): "Caldas de Reyes. -Calda de Cuntis", SPE, 41, 321-323; Neira de Mosquera, A. (12-12-1852): "El Pico-Sagro", SPE, 50, 394-396; Neira de Mosquera, A. (9-1-1853): "Paso del río Ulla por San Juan da Cova", SPE, 2, 9-11; Anónimo (1-6-1856): “Desfiladeros de La Coruña”, SPE, 22, 169.
} 
el itinerario hasta el monumento e informa de la historia de su construcción y de su conveniente situación en la red comercial gallega; destacaremos que junto a la alabanza del "paisaje ameno y pintoresco", se aprovecha la ocasión para transcribir la cita de un "pintor español contemporáneo el Poussin de las ruinas", donde se reflexiona sobre el potencial de las riquezas gallegas junto a su abandono consuetudinario, situación contra la cual, si se tomaran medidas, permitirían un "adelante Galicia" que convertiría a esta región peninsular en una de las europeas más prósperas. En la misma línea de este último juicio, la presentación de las Caldas de Reyes y de Cuntis (Pontevedra) -pasando por la etimología del topónimo, por el contraste con otros tantos balnearios españoles y portugueses encabezados por la palabra Caldas, por los diversos modos de baño en las dos sedes gallegas, por la composición de sus aguas y por su eficacia según las enfermedades, asimismo por la presentación de la escultura romana que recoge el grabado de cabecera, junto a otros valores arqueológicos, y por la descripción de los antiguos edificios que albergan dichos baños-, acaba por juzgar que se trata de unas “(...) aguas minerales que pueden sostener una comparación facultativa con las más celebradas de Francia y Alemania".

Por su parte, el Pico Sagro (A Coruña) suscita una larga prosa admirativa ante la belleza paisajística del paraje en sí y de las vistas que del mismo se contemplan. Si desde este punto se puede avanzar hacia San Juan da Cova, accediendo por aquí al paso del río Ulla, el texto que versa sobre este otro accidente, hace de nuevo gala de capacidad descriptiva, rasgo que señalamos como característico del escritor de los últimos cuatro itinerarios ordenados, Antonio Neira de Mosquera, viajero ya visto con anterioridad y al que volveremos en el apartado correspondiente (2.6.). El dato y rasgo nos parecen relevantes dado que, en otras de las colaboraciones fichadas del mismo autor, se entiende que el mismo manifestaba ya un potencial viajero y turístico gallego, lo cual justificaría en ocasiones sus afanes ponderativos de la belleza galaica y de determinados destinos, comparados con los continentales del mismo tipo.

El Semanario Pintoresco Español incide en la presentación de cinco ciudades gallegas a lo largo de siete entregas ${ }^{27}$. Las cuatro primeras, bajo el pie de "España pintoresca", tratan de Santiago, Ourense y Tuy. De la capital santiaguesa se da cumplida información de orden histórico y monumental. Chocan las llamadas de su relator sobre un cierto "devaneo arqueológico" que le permitió transitar a sus anchas por los tejados de los monumentos y ver la ciudad a vista de pájaro; y asimismo su extensa descripción de un Santiago atípico, convertido en una urbe desordenada y bulliciosa, contraria al perfil consensuado de ciudad recogida y provinciana:

(...) el Santiago de nuestros días es una ciudad estevada y monstruosa, con sus calles revueltas, locas, que se parecen à inmensos vivoreznos que juegan con la basílica del Zebedeo, que es como si dijéramos el boa de la población. Calles que se juntan, se descuajan, se muerden unas à otras como témpanos de piedra, se enredan cerca de un templo, y vomitando jente en una plaza ó cosa parecida, y por decirlo de una vez, calles angulosas que ora se acurrucan formando rueda, ora se atropellan unas à otras como caballos en el juego del campanario. Al N. se distingue desde la torre del reló un tropel de casas sin órden, sin fachada à una calle determinada, vueltas de espaldas unas con otras $(\ldots)$.

${ }^{27}$ Neira de Mosquera, A. (14-4-1844): "España pintoresca. La ciudad de Santiago", SPE, 15, 113-115; P.F.G. y C. (14-2-1847): "España pintoresca. Orense. Artículo primero", $S P E$, 7, 49-51; P.F.G. y C. (212-1847): "España pintoresca. Orense. Artículo segundo", $S P E, 8,37-39$; Vicetto y Pérez, V. (11-7-1847): "España pintoresca. La ciudad de Tuy", $S P E, 28,217-218$; J.C. de L. (11-6-1848): "La Coruña", SPE, 24, 185-186; Anónimo (28-3-1852): "Vista de La Coruña", SPE, 13, 97; Bicetto, B. (11-12-1853): "Ferrol. Castillo de San Felipe", SPE, 50, 393-394. 
Los dos artículos acerca de Ourense insisten en sus monumentos religiosos y en sus contenidos artísticos. En contrapartida, A Coruña es celebrada como uno de los principales puertos del noroeste español y fundamental en el tránsito colonial americano, su bahía como una de las más hermosas de Europa y la industria naviera como una de las más activas; y cuando elogia la capital gallega, el autor se expresa en los siguientes términos:

Por lo demás, al paso que algunos distritos de España parece que van declinando de día en día, en cuanto a población, industria y bienestar, Galicia sigue una marcha enteramente contraria, fomentando sus intereses materiales, en los cuales estriba la verdadera riqueza de los pueblos.

Casi en su totalidad, acompañados de grabados de gran calidad $-\mathrm{y}$ pensamos que cabe entender como expresión del gusto de la publicación por las ilustraciones arquitectónicas el homenaje que se hace al fallecido pintor Genaro Pérez Villaamil, reproduciendo el interior de una iglesia del siglo XII transitada por unos tipos populares ${ }^{28}$-, una larga serie de colaboraciones están dedicadas a monumentos e instituciones gallegas. Este es el caso, casi por lógica, de la catedral, conventos, universidad, hospital, etc. compostelanos ${ }^{29}$. Así mismo, textos y grabados ilustran la existencia de monumentos sitos en ciudades y otros parajes galaicos, en algunas ocasiones con cierta asiduidad como es el caso de Lugo ${ }^{30}$. De todos los documentos presentados se da tanto descripción arquitectónica y artística como histórica, insistiendo en los acontecimientos allí sucedidos así como informando sobre las personalidades relacionados con tales sedes.

${ }^{28}$ A. (19-4-1857): “Un dibujo inédito de D. Genaro Pérez Villaamil”, SPE, 16, 121.

${ }^{29}$ Gil, J. M. (17-11-1839): "España pintoresca. La catedral de Santiago", SPE, 46, 361-364; Neira de Mosquera, A. (21-7-1844): "España pintoresca. Convento S. Martín Pinario", SPE, 29, 228-229; Grabado (3-5-1845) "Convento de San Martín de Santiago", SPE, 18, 144; Neira de Mosquera, A. (18-5-1845): "La universidad de Santiago", SPE, 20, 153-155; Vicetto y Pérez, B. (29-8-1847): "La torre de Hércules", SPE, 35, 275-277; Anónimo (17-12-1848): "Vista del Seminario de Santiago", SPE, 51; 405; Figueroa, R. R. (24-2-1850): "Grande hospital de Santiago", SPE, 8, 38-39; Anónimo (14-11-1852): "Grande hospital de Santiago", $S P E, 46,361-362$; Neira de Mosquera, A. (28-11-1852): "El Estudio viejo de Santiago. El obispo D. Diego de Muros", $S P E$, 48, 379-381; Neira de Mosquera, A. (22-10-1854): "Galicia monumental. Pórtico antiguo de la calle de Bonaval (Santiago)", SPE, 43, 337-339; Grabado (20-10-1854): "Fachada principal del antiguo colegio de S. Gerónimo", $S P E, 44,345$.

${ }^{30}$ J. P. (25-9-1842): “Antigüedades de Lugo", SPE, 39, 312; Armesto, F. (2-10-1842): “Antigüedades de Lugo", $S P E, 40,315-316$; Teixeiro, J. (5-11-1843): "España pintoresca. Catedral de Lugo", SPE, 45, 353-356; Neira de Mosquera, A. (9-6-1844): "España artística. Colegio de Humanidades en Monforte de Galicia", SPE, 23, 177-178; Neira de Mosquera, A. (4-8-1844): "Galicia pintoresca. Las torres de Altamira", SPE, 31, 245-246; Neira de Mosquera, A. (12-9-1847): "España pintoresca. El palacio de los Torrechanos vulgo Churruchaos", SPE, 37, 289-291; B.V.P. [Vicetto Pérez, B.] (27-2-1848): "El castillo de san Antón", $S P E, 9$, 66-67; Neira de Mosquera, A. (21-4-1850): "El puente de Curzul", SPE, 16, 125126; Teijeiro, J. (12-5-1850): "Casa Consistorial de Lugo", SPE, 19, 146-147; Neira de Mosquera, A. (22-9-1850): "Antigüedades españolas. Mosaico romano de Lugo", SPE, 38, 301-302; Neira de Mosquera, A. (6-10-1850): "La muralla romana de Lugo", $S P E$, 40, 313-314; Neira de Mosquera, A. (16-3-1851): "Puente de Lugo", SPE, 11, 84-85; Neira de Mosquera, A. (10-8-1851): "El hospital de Lugo", SPE, 32, 254-255; Anónimo (7-12-1851): "Iglesia de Marcelle", $S P E, 49,387$; Anónimo (21-12-1851): "La fábrica de Sargadelos", $S P E, 51,405-406$; Neira de Mosquera, A. (1-2-1852): "Las torres de oeste", SPE , 4, 26-27; Figueroa, J. R. (16-1-1853): “Antigua colegiata de Sar", SPE, 3, 19-20; Vicetto (20-11-1853): " Castillo de Andrade", SPE, 47, 369; Vicetto, B. J. (12-2-1854): "Ferrol. Iglesia Parroquial de san Julián", SPE, 7, 49-50; Grabado (26-2-1854): "Ferrol. Convento de san Francisco", SPE, 9, 65; Vicetto, B. J. (5-3-1854): "Ferrol. Convento de san Francisco", SPE, 10, 74-75; Anónimo (14-10-1855): "La catedral de Mondoñedo", SPE , 41, 321; Sota, P. de la (10-2-1856): "El convento de S. Francisco en Orense", SPE, 6, 42-43; Murguía, M. (26-10-1856): "El castillo de Bayona de Galicia", SPE, 43, 339-340; Villaamil y Castro, J. (6-12-1857): “San Martín de Mondoñedo", SPE, 49, 387-391. 
Por tanto este material coincide también en el contenido del apartado (2.1.). En conjunto podemos destacar que, si bien las aportaciones se centran en la galleguidad de dichos testimonios, no obstante suele apreciarse el deseo por que se tenga en cuenta la proyección española de los mismos.

2.6. Son pocos los testimonios relativos a viajes y viajeros por el territorio gallego en el Semanario Pintoresco Español. No obstante, un "anuncio" divulga exprofeso un folleto con el título Guía del viajero en la catedral de Santiago, que revisa la historia y el contenido artístico de la Sede al tiempo que, casi publicitariamente, acaba opinando: "recomendamos muy eficazmente á nuestros lectores la adquisición de esta obra, lujosamente impresa con cuatro láminas tiradas a parte en magnífico papel vitela". Pero si en ese caso podemos exagerar el alcance turístico, explícito del todo nos parece la siguiente invitación a favor del potencial viajero de Galicia, de acuerdo con artículo mencionado en (2.5.) ${ }^{31}$. A pesar de estas llamadas, la revista solo recoge crónicas viajeras por Galicia en la medida en que recuperemos aquellos textos del apartado (2.5.). Allí ya destacábamos la figura de Antonio Neira de Mosquera de quien, junto a la capacidad descriptiva de los suyos, habría que valorar ahora el correlato de sus itinerarios hasta los lugares descritos, con los modelos de prosa romántica. Con todo, puestos a presentar una ciudad o paraje, los itinerarios suyos o de otros autores hasta el destino en cuestión, suelen contener fórmulas habituales en las guías viajeras: es el caso de "Siguiendo el rumbo de la ría de Vigo hacia el este, á 16 millas marítimas de su entrada...", que nos aproximará a la isla de san Simón, o "Desde el Puente-Ulla se acerca el viajero por un sendero...", que nos conducirá hasta san Xoán da Cova ${ }^{32}$. Con todo, nos hubiera gustado poder destacar el estudio de una "famosa expedición a Santiago de Galicia", como un precoz documento de literatura viajera, pero debemos aceptar que se trata de un testimonio de literatura bélica pues narra la incursión y destrucción de Almanzor en tierras gallegas, por lo que debería resituarse en el apartado de historia (2.1.) $)^{33}$.

3. No querríamos acabar estas páginas sin hacer mención a las firmas que contribuyeron activamente con artículos de contenido gallego en el Semanario Pintoresco Español. Destacan entre todos ellos la participación de Antonio Neira de Mosquera (1818-1853), que también firma Antonio Neira, con veintinueve colaboraciones. Historiador, periodista, narrador y dramaturgo compostelano publica en el Semanario esencialmente materia histórica, pormenorizadamente documentada y desarrollada, algunos de cuyos artículos se incorporaron al índice del volumen Monografías de Santiago (1850). Con ocho títulos y con las diversas firmas de Benito Vicetto y Pérez, Benito Bicetto, B. V. P., Vicetto o Benito José Vicetto (1824-1878), el conocido polígrafo ferrolano, da probada cuenta de sus conocimientos de historia gallega cuando informa sobre ciudades o monumentos galaicos. José Rúa Figueroa o J. R. Figueroa o, pensamos también que R. R. Figueroa (1820-1855), escribe con contenidos gallegos en el Semanario en cinco ocasiones. Político y escritor, con estudios en medicina y producción teatral, interesa aquí su veta romántica tanto por ser uno de los introductores de la tradición ossiánica como por atender a la literatura de Chateaubriand. Tres son las aportaciones que firma José Villaamil

${ }^{31}$ Anónimo (19-9-1847): “Anuncio”, SPE, 38, 304; Neira de Mosquera, A. (2-5-1852): "El puente Cesures", SPE, 18, 140-142.

${ }^{32}$ Taboada y Leal, N. (5-6-1842): "Descripción de las islas de san Simón y san Antonio en la ría de Vigo", $S P E$, 32, 181-182; Neira de Mosquera, A. (9-1-53): "Paso del río Ulla por san Juan da Cova", $S P E$, 2, 9-11.

${ }^{33}$ Simonet, F. J. (19-7-1857): "Famosa expedición a Santiago de Galicia por el Hagib Almanzor (1)", $S P E, 29$, 226-229; Simonet, F. J. (6-8-1857): "Famosa expedición a Santiago de Galicia por el Hagib Almanzor (Conclusión)", SPE, 33, 259-262. 
y Castro, o Villa-Amil y Castro (1838-1910), madrileño de ascendencia gallega y crecido en Mondoñedo (Lugo), con importante presencia institucional académica tanto en Galicia como en Madrid, y con colaboraciones de contenido histórico y arqueológico que coinciden con la materia fundamental de sus publicaciones. De la figura por todos conocida de Manuel Murguía (1833-1923) damos cuenta de un par de entradas, seleccionadas por su contenido, así como de las de José Teixeiro o Teijeiro y Vamonde (s.f.), procurador en Lugo y estudioso de la romanización en Galicia, cuya contribución en el Semanario se relaciona con su principal actividad. Junto a este último, participan con una aportación suelta los siguientes colaboradores: Manuel de Assas y Ereño (1813-1880), cántabro, director del Semanario entre 1839 y 1857, arqueólogo e historiador, inauguró la cátedra de sánscrito en la Universidad Central de Madrid, por sus tendencias filoarias mostró un interés especial por la cultura celta ${ }^{34}$; Francisco Javier Armesto (s.f.), jurisconsulto y autor de unos "Apuntes concernientes al vestigio romano descubierto en la calle Batitales de la ciudad de Lugo" (1843), opúsculo publicado en colaboración por la Real Sociedad Económica de Amigos de Lugo, habiendo llevado a cabo la lectura en la citada Sociedad, y publicado un resumen con el encabezamiento "Consideraciones..." en el Semanario, material que remite al mosaico hallado en dicha calle lucense en septiembre de 1842, descubrimiento también tratado por A. Neira de Mosquera en 1850. Francisco Fabre (s.f.), por coincidencia con la materia de su colaboración, identificado como el autor de un "Ensayo sobre la historia geográfica del norte del globo", publicado en Revista de España y del extranjero (1842); José María Gil Rey (1815-1853), botánico y etnógrafo con gran repercusión en viajeros y eruditos ochocentistas, merced fundamentalmente a su trabajo en el Semanario sobre la catedral compostelana -texto que suscitó la publicación de guías del mismo asunto, entre ellas una de 1847, editada por B. González, estimado por algunos su autor, y que fue anunciada en el propio Semanario (2.6.)-; Pío de la Sota y Lastra (1819-1893), jurisconsulto y narrador cántabro, firmante del volumen Colección de ensayos literarios y dramáticos (1853) y así mismo de estudios de conventos e iglesias ourensanas, materia a la que remite su colaboración en el citado Semanario; Francisco Javier Simonet y Baca (1829-1897), arabista e historiador malagueño afincado en Madrid, su colaboración en nuestra publicación acerca de la expedición de Almanzor a Galicia formaría parte del volumen que publicaría un año después, Leyendas históricas árabes (1858); Nicolás Taboada y Leal (1798-1883), médico y cronista vigués, su artículo sobre san Simón y san Antonio deriva de su volumen Descripción topográfico-histórica de la ciudad de Vigo, su ría y alrededores (1840); Vicente Vázquez Varela (s.f.), quien escribe sobre un curioso caso de parasismo, cuyo texto pasaría tres años después a formar parte del volumen VIII, en el apartado "Miscelánea", de la revista canaria El Instructor ó Repertorio de Historia, Bellas Letras y Artes (Londres, 1841), que tras ese volumen reaparecerá con el nombre de El Auxiliar.

En nuestra publicación surgen también dos pseudónimos. Detrás de la denominación de El Barón de Illescas se ocultaba el nombre del toledano Nicolás Ramírez de Losada (1817-1888), autor de literatura satírica de mucho éxito como, por ejemplo, El Libro de los Retratos (1850), su pseudónimo quizá derivara del personaje de la comedia moratiniana El Barón, protagonizada por el Barón de Montepino, que se desarrolla en Illescas, estrenada en 1803 en el madrileño Teatro de la Cruz. Por último, El Fisgón Invisible nos lleva a la identificación con José María Anduela o, quizás, de Andueza (1809-1865) que también firmara con el pseudónimo de Aben-Zaide, periodista, novelista histórico y costumbrista que se estableció en La Habana entre 1825 y 1830, experiencia a la que remiten algunos de

${ }^{34}$ Para completar información véase el trabajo de Vidal (2013). 
sus escritos, tanto los que aparecen firmados por el segundo nombre como el firmado por El Fisgón Invisible.

A parte de los autores con rúbrica, hay unos pocos artículos anónimos, generalmente pies de grabados, y algunas iniciales sin identificar por nuestra parte, como es el caso de A., J. C. de L., J. M. G. L. o G. L., J. T., N. C. C., P. J. G. y C. o P. F. G. y C., estos últimos todos con una sola colaboración.

\section{REFERENCIAS BIBLIOGRÁFICAS}

Arroyo Almaraz, Antonio (ed.) (2012): Literatura y prensa romántica: El Artista y el Semanario Pintoresco Español en sus aniversarios. Madrid: CSIC (número especial de Arbor, 188/757).

Fernández García, Antonio (1992): Europa en el Semanario Pintoresco Español. Madrid: Ayuntamiento / Instituto de Estudios Madrileños.

Fuentes, Juan Francisco y Javier Fernández Sebastián (1998): Historia del periodismo español. Madrid: Editorial Síntesis.

Fuentes Barco, Marina, S. García Piñeiro y Tiburcio Angosto Saura (2006): "La santa de Gonzar, un caso de inedia desde la perspectiva de la fisiología del siglo xix", Frenia 6, pp. 207-218.

HeRnández SÁnchez, Antonio (2012): "El País Vasco en las revistas ilustradas españolas del siglo XIX y principios del XX" (disponible en: www.fsancho.sabio.es/html/SEMANARIO\% 20PINTORESCO\%20ESPAÑOL.html) [consulta 22/10/2014].

NaVAs SÁnchez-Élez, María Victoria y Juan Miguel Ribera Llopis (2014): "Semanario Pintoresco Español (1836-1857): noticias sobre la cultura portuguesa”, en Á. Marcos de Dios (ed.), La lengua portuguesa. Vol. 1. Estudios sobre literatura y cultura de expresión portuguesa. Salamanca: Universidad, pp. 811-822.

Sánchez Aranda, José Javier y Carlos Herrera (1992): Historia del periodismo español. Desde sus orígenes hasta 1975. Pamplona: Universidad de Navarra.

Seonne, María Cruz (1983): Historia del periodismo en España. 2. El siglo XIX. Madrid: Alianza Editorial.

VIDAL, Jordi (2013): "La introducción de las teorías raciales en la arqueología española: Manuel de Assas y Ereño", Complutum 24/1, pp. 59-67. 